\title{
Clinical Profile of Community Acquired Pneumonia (CAP) in Patients with Type 2 Diabetes Mellitus - A Hospital Based Study
}

\author{
Ganesh V. Shetty ${ }^{1}$, Sharath P. Madhyastha², Balaraj K.P. ${ }^{3}$, \\ Charan Thej Reddy ${ }^{4}$, Avinash Holla ${ }^{5}$, Akhila Doddamani ${ }^{6}$
}

1, 2, 4, 5 Department of Medicine, Kasturba Medical College, Manipal Academy of Higher Education, Manipal, Karnataka, India. ${ }^{3}$ Department of Medicine, Kempegowda Institute of Medical Sciences, Bangalore, Karnataka, India. ${ }^{6}$ Department of Community Medicine, Kasturba Medical College, Manipal Academy of Higher Education, Manipal, Karnataka, India.

\section{ABSTRACT}

\section{BACKGROUND}

It is well known fact that diabetics are prone to develop infections and have increased mortality and morbidity than non-diabetics. However, the effect of diabetes mellitus on the risk of pneumonia remains uncertain. We wanted to study the aetiology, clinical features, and the outcome of pneumonia in diabetic patients.

\section{METHODS}

A comparative observational study was conducted in a tertiary care hospital, southern India which included 50 diabetic patients with pneumonia and 50 nondiabetic patients with pneumonia. Clinical characteristics, $x$-ray findings, aetiological agents, and outcome of diabetic patients were analysed and compared with data from the control group.

\section{RESULTS}

Diabetic patients with pneumonia were more unwell at the time of admission in the form of high PSI (Pneumonia Severity Index) score $\left(\mathrm{p}=0.004^{* *}\right)$, intensive care admissions and prolonged hospital stay $\left(\mathrm{p}=<0.001^{* *}\right)$. Diabetic patients were significantly associated with multilobar involvement $\left(\mathrm{p}=0.045^{*}\right)$. There was no significant difference in age, gender, coexisting underlying disease and complications. In patients with diabetes mellitus, mortality was associated with multilobar infiltrate, increased PSI score $\left(\mathrm{p}=0.078^{*}\right)$ at admission.

\section{CONCLUSIONS}

These is a significant difference between pneumonia in diabetics compared with nondiabetics. Diabetic patients had presented with higher PSI score, required more ICU admissions and had prolonged hospitalization. Diabetes is also associated with bad prognosis and high mortality.
Corresponding Author: Dr. Sharath Madhyastha P, Assistant Professor, Department of Medicine, Kasturba Medical College, Manipal Academy of Higher Education, Manipal - 576104, Udupi, Karnataka, India. E-mail:dr.sharathymc@gmail.com

DOI: $10.14260 /$ jemds/2020/698

How to Cite This Article:

Shetty GV, Madhyastha SP, Balraj KP, et al. Clinical profile of community acquired pneumonia (CAP) in patients with type 2 diabetes mellitus - a hospital based study.J Evolution Med Dent Sci 2020;9(43):31813185, DOI: 10.14260/jemds/2020/698

Submission 08-08-2020,

Peer Review 16-09-2020,

Acceptance 22-09-2020,

Published 26-10-2020.

Copyright (c) 2020 Ganesh V. Shetty et al. This is an open access article distributed under Creative Commons Attribution License [Attribution 4.0 International (CC BY 4.0)]

\section{KEY WORDS}

Pneumonia, Diabetes, Pneumonia Severity Index 


\section{BACKGROUND}

Community-Acquired Pneumonia (CAP) is defined as "an acute infection of the pulmonary parenchyma in a patient who has acquired the infection in the community." The clinical presentation of CAP varies, ranging from mild pneumonia characterized by fever and productive cough to severe pneumonia characterized by respiratory distress and sepsis. Because of the wide spectrum of associated clinical features, CAP is a part of the differential diagnosis of nearly all respiratory illnesses. CAP is a frequent and potentially life threatening illness. It is associated with substantial morbidity and mortality, particularly in older adult patients and those with significant comorbidities. ${ }^{1}$ CAP is a leading cause of death worldwide. The occurrence of CAP implies either a fault in host defences, contact with a virulent micro-organism or an overwhelming inoculum. ${ }^{2}$

In addition to above mentioned factors, comorbidities in the host may impair the pulmonary defence function and can lead to increased risk of pneumonia. These include older age, chronic lung diseases and immunocompromising conditions like diabetes mellitus (DM). ${ }^{3}$

Viral respiratory tract infections can lead to primary viral pneumonias and also predispose to secondary bacterial pneumonia. This is most pronounced for influenza virus infection. Conditions that increase risk of macro aspiration of stomach contents and / or micro aspiration of upper airway secretions predispose to CAP, such as alteration in consciousness (e.g. due to stroke, seizure, anaesthesia, drug or alcohol use) or dysphagia due to oesophageal lesions or dysmotility. Smoking, alcohol overuse (e.g. $>80 \mathrm{~g} /$ day), and opioid use are key modifiable behavioural risk factors for CAP. Other factors that have been associated with an increased risk of CAP include crowded living conditions (e.g. prisons, homeless shelters), residence in low-income settings, and exposure to environmental toxins. ${ }^{3}$

The most commonly identified causes of CAP can be grouped into three categories. They are (1) Typical bacteria (eg, S. pneumoniae (most common bacterial cause), $H$. Influenza, Staphylococcus aureus, Group A streptococci, aerobic gram-negative bacteria like Klebsiella spp or Escherichia coli). (2) Atypical bacteria (e.g. Legionella, Mycoplasma, Chlamydia). (3) Respiratory viruses (e.g. Influenza A and B viruses, Rhinoviruses, Parainfluenza viruses, Adenoviruses, Respiratory Syncytial virus, Corona virus). The relative prevalence of these pathogens varies with geography, pneumococcal vaccination rates, host risk factors (e.g. smoking), season, and pneumonia severity.

Most studies support an increased risk of infection amongst patients with diabetes mellitus compared with the general populace, although the magnitude of this risk is uncertain. ${ }^{4}$ Host- and organism-specific issues that may enlighten why diabetic patients are more vulnerable to particular infections. Several aspects of immunity, such as specific neutrophil functions like chemotaxis, endothelial adherence, phagocytosis, intracellular bactericidal action and cell-mediated immunity are all lowered in uncontrolled diabetes mellitus. 5

Numerous studies have proved that diabetic patients consult healthcare facility for infections more frequently than non-diabetics. ${ }^{6}$ The risk of infection in diabetes is directly related to degree of hyperglycemia. ${ }^{7}$ Nevertheless it is still unclear as to whether pneumonia in diabetics has specific clinical manifestations, high mortality or involves more virulent pathogens. The present study is therefore undertaken to identify the clinical, radiological findings, the etiological agents and the outcome of pneumonia in diabetes mellitus.

\section{METHODS}

A comparative observational study conducted in a tertiary care hospital, southern part of India which included 50 patients of pneumonia with diabetes and similar age and gender matched 50 patients of pneumonia in non-diabetics. The study was conducted for a period of 2 years, from September 2011 to September 2013. This was approved by the Institutional Ethical Committee (IEC). All patients were assessed clinically by thorough history and general physical and systemic examination.

Diabetes mellitus was diagnosed based on ADA (American Diabetic Association) guidelines. That is when FBS (fasting plasma sugar) more than $126 \mathrm{mg} / \mathrm{dl}$, and / or PPBS (2 hour post prandial blood sugar) more than $200 \mathrm{mg} / \mathrm{dL}$ or glycated haemoglobin (HbA1c) more than $6.5 \%{ }^{8,9}$ However, previously diagnosed diabetic cases were confirmed by verifying the old case sheet and medication chart.

Routine blood tests like complete blood count (CBC), erythrocyte sedimentation rate (ESR), kidney and liver function tests, RBS (Random Blood Sugar), FBS, PPBS, HbA1c and urine microscopy were done in all the patients on admission. The tests were repeated as and when needed. Sputum was sent for gram staining, culture and antibiotic sensitivity, before institution of antibiotics. In all the patients' chest radiography was taken on day of admission and one week post antibiotic therapy. Computed Tomography (CT) and Ultrasound thorax were also done in some selected cases. The clinical characteristics, x-ray findings, etiological agents, admission PSI score ${ }^{10}$ (Table 1), need of intensive care unit (ICU), complications and total duration of hospital stay of diabetic patients were analysed and compared with data taken from control group.

\section{Inclusion Criteria}

Type II diabetic patients and non-diabetic patients who satisfy bellow mentioned criteria:

1. Classical symptoms suggestive of pneumonia such as pyrexia, productive or dry cough, with or without chest pain or dyspnoea.

2. Chest radiography suggestive of pneumonia in the form of unilateral or bilateral homogenous or non-homogenous opacities.

3. Blood investigation shows presence of leukocytosis with neutrophilia / lymphocytosis, elevated ESR.

4. Sputum gram staining and culture growing pathological organisms.

\section{Exclusion Criteria}

Patients with hospital acquired pneumonia, aspiration pneumonia and HIV positive or with other immune compromised states are excluded from the study. 


\begin{tabular}{|c|c|}
\hline Risk Factors & Points \\
\hline \multicolumn{2}{|l|}{ Demographic Factors } \\
\hline Age for a Man & Age (in years) \\
\hline Age for a Woman & Age (in years) - 10 \\
\hline Nursing Home Resident & +10 \\
\hline \multicolumn{2}{|l|}{ Coexisting Illnesses } \\
\hline Neoplastic Disease (Active) & +30 \\
\hline Chronic Liver Disease & +20 \\
\hline Heart Failure & +10 \\
\hline Cerebrovascular Disease & +10 \\
\hline Chronic Renal Disease & +10 \\
\hline \multicolumn{2}{|c|}{ Physical Examination Findings } \\
\hline Altered Mental Status & +20 \\
\hline Respiratory Rate $\geq 30$ / minute & +20 \\
\hline Systolic Blood Pressure $<90 \mathrm{mmHg}$ & +20 \\
\hline Temperature $<35^{\circ} \mathrm{C}$ or $\geq 40^{\circ} \mathrm{C}$ & +15 \\
\hline Pulse $\geq 125$ beats / minute & +10 \\
\hline \multicolumn{2}{|c|}{ Laboratory and Radiographic Findings } \\
\hline Arterial $\mathrm{pH}<7.35$ & +30 \\
\hline Blood Urea Nitrogen $\geq 30 \mathrm{mg} / \mathrm{dL}(11 \mathrm{mmol} / \mathrm{L})$ & +20 \\
\hline Sodium $<130 \mathrm{mmol} / \mathrm{L}$ & +20 \\
\hline Glucose $\geq 250 \mathrm{mg} / \mathrm{dL}(14 \mathrm{mmol} / \mathrm{L})$ & +10 \\
\hline Haematocrit $<30 \%$ & +10 \\
\hline Partial Pressure of Arterial Oxygen < $60 \mathrm{mmHg}$ & +10 \\
\hline Pleural Effusion on Chest Radiograph & +10 \\
\hline PSI Class & Mortality (Percent) \\
\hline No Predictors & 0.1 \\
\hline$\leq 70$ & 0.6 \\
\hline 71 to 90 & 0.9 \\
\hline 91 to 130 & 9.3 \\
\hline$>130$ & 27.0 \\
\hline \multicolumn{2}{|c|}{ Table 1. Pneumonia Severity Index (PSI)10 } \\
\hline
\end{tabular}

\section{Statistical Analysis}

Patients were divided into two groups, pneumonia in diabetics (Study Group - SG) and pneumonia in non-diabetics (Control Group - CG). Statistical analysis was done using SPSS (version 15.0, South Asia Bangalore) computer software. Qualitative data were presented as frequency and percentages and analyzed using chi-square test or fisher's exact test (in case of $2 \times 2$ contingency tables). Unpaired " $\mathrm{t}$ " test was used to determine the mean difference between diabetes and nondiabetes group. Quantitative data was presented as mean and standard deviation (SD) and ' $p$ ' values less than 0.05 were considered significant.

\section{RESULTS}

A total number of 100 pneumonia cases were analysed, out of which 50 cases were pneumonia in diabetics (Study Group $\mathrm{SG}$ ) and 50 cases were pneumonia in non-diabetics (Control Group - CG).

The average age in diabetic group (SG) was $57.72 \pm 8.25 \mathrm{yr}$. and in non-diabetic group (CG) was $56.88 \pm 9.39$ yrs. Most of the study population (74\% in SG and $72 \%$ in CG) were between 51 to $70 \mathrm{yr}$. Samples are age matched with $\mathrm{p}=0.636$. In both groups male patients (58 \% in CG and $54 \%$ in SG) are slightly more compared to female patients. There was no statistically significant difference regarding gender in both the groups. Both the groups are gender matched with $\mathrm{p}=0.687$.

The most common symptoms in both the groups were fever, cough, and expectoration. Around half of the study subjects had dyspnoea. Few patients complained chest pain and haemoptysis. Chronic obstructive airway disease was the most common co morbidity present in CG and SG (14\% vs. 16 $\%$ ), followed by coronary artery disease (CAD) (10 \% vs. 16 $\%)$. There was no statistically significant variation in terms of co-morbidities in between two groups. There was no statistically significant difference in habits (alcohol and smoking) between two groups. (Table 2)

\begin{tabular}{|c|c|c|c|}
\hline Clinical Manifestation & $\begin{array}{l}\text { Diabetics } \\
(n=50)\end{array}$ & $\begin{array}{c}\text { Non - } \\
\text { Diabetics } \\
(n=50)\end{array}$ & $\begin{array}{c}P \\
\text { Value }\end{array}$ \\
\hline Fever & $44(88)$ & $43(86)$ & 0.766 \\
\hline Cough & $50(100)$ & $46(92)$ & 0.117 \\
\hline Expectoration & $50(100)$ & $46(92)$ & 0.117 \\
\hline Breathlessness & $27(54)$ & $24(48)$ & 0.548 \\
\hline Chest Pain & $10(20)$ & $7(14)$ & 0.424 \\
\hline Haemoptysis & $2(4)$ & $1(2)$ & 0.558 \\
\hline \multicolumn{4}{|c|}{ Concomitant Underlying Illness } \\
\hline Neoplasm & $0(0)$ & $1(2)$ & 0.317 \\
\hline Congestive Cardiac Failure (CCF) & $1(2)$ & $1(2)$ & 1 \\
\hline Asthma & $2(4)$ & $3(6)$ & 0.646 \\
\hline Ischemic Heart Disease (IHD) & $8(16)$ & $5(10)$ & 0.372 \\
\hline Chronic Obstructive Pulmonary Disease (COPD) & $8(16)$ & $7(14)$ & 0.779 \\
\hline Cerebro-Vascular Accidents (CVA) & $5(10)$ & $3(6)$ & 0.461 \\
\hline Chronic Kidney Disease (CKD) & $5(10)$ & $3(6)$ & 0.461 \\
\hline Others & $4(8)$ & $4(8)$ & 1 \\
\hline \multicolumn{4}{|l|}{ Habits } \\
\hline Smoking & $15(30)$ & $12(24)$ & 0.499 \\
\hline Alcohol & $8(16)$ & $6(12)$ & 0.564 \\
\hline \multicolumn{4}{|c|}{$\begin{array}{l}\text { Table 2. Clinical Manifestation, Concomitant } \\
\text { Underlying Illness and Habits }\end{array}$} \\
\hline
\end{tabular}

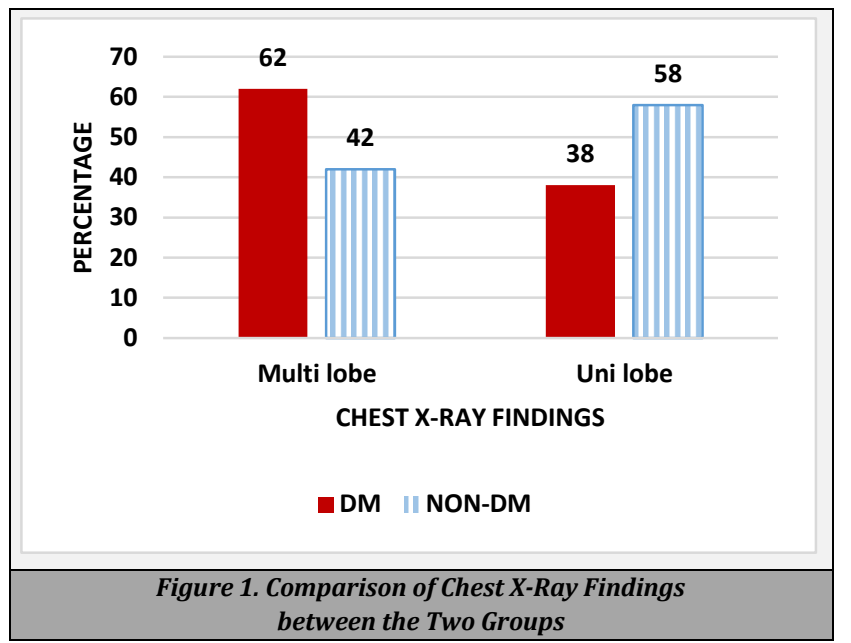

\begin{tabular}{|c|c|c|c|}
\hline Variables & DM Group & Non DM Group & P Value \\
\hline Haemoglobin & $10.90 \pm 1.55$ & $12.81 \pm 1.80$ & $0.001^{* *}$ \\
\hline Total count & $8583.00 \pm 4012.70$ & $7266.00 \pm 2272.88$ & $0.046^{*}$ \\
\hline ESR & $37.58 \pm 29.64$ & $27.26 \pm 19.35$ & $0.042^{*}$ \\
\hline Blood Urea & $36.06 \pm 17.77$ & $31.54 \pm 15.29$ & 0.176 \\
\hline Creatinine & $1.05 \pm 0.52$ & $0.90 \pm 0.40$ & 0.100 \\
\hline \multicolumn{4}{|c|}{ CXR Findings } \\
\hline Multi lobe & $31(62)$ & $21(42)$ & $0.045^{*}$ \\
\hline Uni-lobe & $19(38)$ & $29(58)$ & \\
\hline \multicolumn{4}{|c|}{ Sputum Gram Staining } \\
\hline GNB & $21(42)$ & $15(30)$ & 0.212 \\
\hline GPC & $18(36)$ & $31(62)$ & $0.009^{* *}$ \\
\hline GPC / GNB & $12(24)$ & $4(8)$ & $0.029^{*}$ \\
\hline \multicolumn{4}{|c|}{ Sputum Culture } \\
\hline 1. Strep. pneumonia & $14(28)$ & $21(42)$ & 0.142 \\
\hline 2. Staph. aureus (MRSA / MSSA) & $3(6)$ & $10(20)$ & $0.03^{*}$ \\
\hline 3. E. Coli & $3(6)$ & $2(4)$ & 0.646 \\
\hline 4. Klebsiella & $7(14)$ & $5(10)$ & 0.538 \\
\hline 5. Citrobacter & $0(0)$ & $2(4)$ & 0.153 \\
\hline 6. Acinetobacter & $3(6)$ & $1(2)$ & 0.309 \\
\hline 7. Pseudomonas Aeruginosa & $5(10)$ & $3(6)$ & 0.461 \\
\hline 8. Enterobacter & $3(6)$ & $2(4)$ & 0.646 \\
\hline 9. Poly Microbial & $12(24)$ & $4(8)$ & $0.029^{*}$ \\
\hline \multicolumn{4}{|c|}{$\begin{array}{l}\text { Table 3. Comparison of Lab Parameters, Chest X-Ray and Sputum } \\
\text { Examination between the Two Groups }\end{array}$} \\
\hline
\end{tabular}

The average blood haemoglobin (Hb) in CG was $12.81 \pm$ 1.80 and in SG $10.90 \pm 1.55$. The difference was statistically significant $\left(\mathrm{p}=0.001^{* *}\right)$, indicating a greater number of patients in study group (diabetics) were anaemic. The TLC 
(Total Leukocyte Count) and erythrocyte sedimentation rate were significantly high in SG compared to CG. The blood urea and creatinine were also high in SG but which was statistically not significant. Deranged RFT in SG was may be related to sepsis or diabetic nephropathy. Involvement of more than two zones in chest radiography (multilobe) was significantly more in diabetic group ( $42 \%$ in CG vs. $62 \%$ in SG) ( $p=0.045^{*}$ ). (Table 3) (Figure 1)

Gram staining reports revealed that Gram positive cocci were significantly high $\left(\mathrm{p}=0.009^{* *}\right)$ in non-diabetic group than diabetic group (62\% vs. $36 \%$ ). A combination of gram positive cocci and gram negative bacilli (GPC / GNB) was significantly ( $p=0.029^{*}$ ) more in study group (SG - $22 \%$ vs. CG - $8 \%$ ). The frequent pathogens on sputum culture in CG were Streptococcus pneumonia (42\%), Staphylococcus aureus $(20.0 \%)$ and Klebsiella pneumonia (10\%). Whereas in SG, Streptococcus pneumonia was found in $28 \%$, followed by Klebsiella pneumonia (14\%) and polymicrobial (24\%). Staph. aureus growth is significantly more in non-diabetics $(\mathrm{p}=$ $0.03^{*}$ ) and polymicrobial growth is significantly more in diabetics $\left(p=0.029^{*}\right)$. (Table 3)

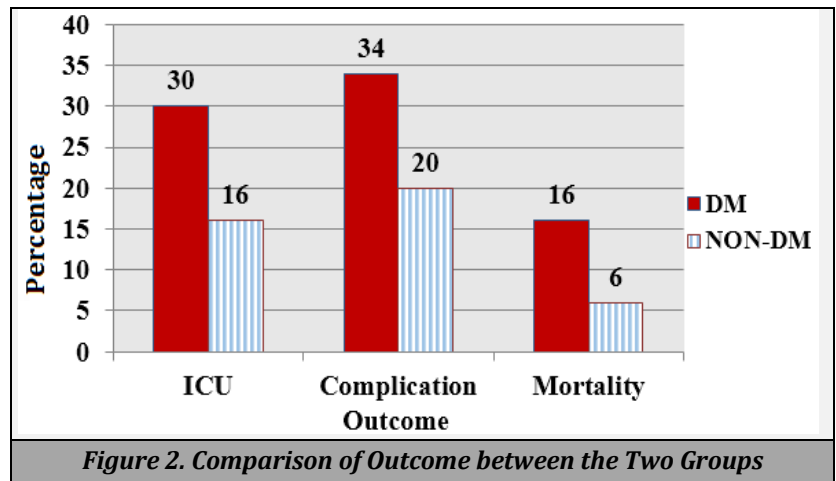

\begin{tabular}{|c|c|c|c|}
\hline Outcome & Diabetics & $\begin{array}{l}\text { Non- } \\
\text { Diabetics }\end{array}$ & P Value \\
\hline ICU Admission & $15(30)$ & $8(16)$ & 0.096 \\
\hline Complications & $17(34)$ & $10(20)$ & 0.114 \\
\hline Mortality (Death) & $8(16)$ & $3(6)$ & 0.110 \\
\hline Duration Hospital Stay Mean \pm SD & $12.80 \pm 2.92$ & $10.20 \pm 2.56$ & $0.001^{* *}$ \\
\hline \multicolumn{4}{|c|}{ Type of Complications } \\
\hline Pleural Effusion & $5(10)$ & $3(6)$ & 0.461 \\
\hline Septic Shock & $11(22)$ & $7(14)$ & 0.299 \\
\hline Renal Failure & $4(8)$ & $1(2)$ & 0.169 \\
\hline MODS & $4(8)$ & $1(2)$ & 0.169 \\
\hline Cardiac Arrest & $3(6)$ & $0(0)$ & 0.079 \\
\hline \multicolumn{4}{|c|}{ PSI Class } \\
\hline I & $11(22)$ & $25(50)$ & $0.004^{* *}$ \\
\hline II & $3(6)$ & $4(8)$ & 0.695 \\
\hline III & $5(10)$ & $5(10)$ & 1 \\
\hline IV & $17(34)$ & $8(16)$ & $0.004^{* *}$ \\
\hline V & $14(28)$ & $8(16)$ & 0.148 \\
\hline PSI score & Diabetics $(N=50)$ & \multicolumn{2}{|c|}{ Non-Diabetics $(\mathrm{N}=50)$} \\
\hline Range & $46-194$ & \multicolumn{2}{|c|}{$35-170$} \\
\hline Mean \pm SD & $97.17 \pm 37.15$ & \multicolumn{2}{|c|}{$83.1 \pm 36.22$} \\
\hline Inference & \multicolumn{3}{|c|}{$\begin{array}{l}\text { Greater PSI score was observed in study group } \\
\text { (diabetics) with } \mathrm{p}=0.078^{*}\end{array}$} \\
\hline \multicolumn{4}{|c|}{$\begin{array}{c}\text { Table 4. Comparison of Outcome, Complications, PSI Class } \\
\text { and Score between the Two Groups }\end{array}$} \\
\hline
\end{tabular}

Need of intensive care (ICU) and pneumonia complications were more in SG. More deaths were noted in diabetics (16\%) in comparison with non-diabetics (6\%). The number of days spent in hospital was also significantly high $\left(\mathrm{p}=0.001^{* *}\right)$ in SG $(12.80 \pm 2.92)$ in comparison with CG $(10.20 \pm 2.56)$. (Figure 2) The pneumonia related complications like synpneumonic effusion (10\% vs. $6 \%$ ), sepsis \& septic shock (22\% vs. $14 \%$ ), kidney failure ( $8 \%$ vs. $2 \%$ ), multi organ dysfunction (8 \% vs. $2 \%$ ), and cardiac arrest (6\% vs. $0 \%$ ) were also more in diabetics but these findings were statistically not significant. Significantly higher PSI class (class IV and V) was observed in diabetic group ( $\mathrm{p}=0.004^{* *}$ for class IV), in comparison with non-diabetic who were largely among PSI class I $\left(p=0.04^{* *}\right)$. PSI score was significantly high in study group (93.43 \pm 38.14 ) in comparison with control group $(80.27 \pm 38.14)$, $(\mathrm{p}=$ 0.078 ). (Table 4)

\section{DISCUSSION}

In the present study, we have compared parameters like age, gender, signs \& symptoms, coexisting underlying illness, addictions, investigations, intensive care admissions, complications, duration of hospital stay, mortality and pneumonia severity index between diabetics and non-diabetic patients with pneumonia were analysed.

It was mentioned in the previous studies that diabetic patients were significantly older than non-diabetic patients and there was a male predominance in diabetics. ${ }^{11,12}$ Even in our study average age of presentation was 58 yrs. with maximum people between 51 - 70 yrs. (74\%). But there was no statistically significant difference concerning gender in both the groups.

Miquel et al had conducted a prospective study included 660 pneumonia patients, out of which 106 were diabetics. More than half of diabetic patients in that study had coexisting underlying illness along with diabetes. Chronic obstructive pulmonary diseases (COPD) is the most common disease among them. ${ }^{11}$ The present study revealed that about $42 \%$ patients had coexisting underlying illness, predominantly COPD (16\%) and IHD (16\%).

A study from Bangladesh reported that Klebsiella pneumoniae to be the most common in diabetic patients; on the other hand, Pneumococcus was the most frequent bacterium causing CAP in non-diabetic subjects. Staphylococcus aureus, E. coli and Pseudomonas aeruginosa were the other bacteria found in the study. ${ }^{13}$ Miquel et al reported that there was no significant difference in causative organisms in patients with diabetes and non-diabetes. ${ }^{11}$ The aetiology of pneumonia may vary with change in study population and geographic areas. ${ }^{14}$ In the present study the frequent pathogens among non-diabetics were Streptococcus pneumonia (42 \%), Staphylococcus aureus (20.0\%) and Klebsiella pneumonia (10\%). In the study group (diabetics), Streptococcus pneumonia (28\%), Klebsiella pneumonia (14\%) and Polymicrobial (24\%). Staphylococcus aureus growth is significantly more in non-diabetics $\left(\mathrm{p}=0.03^{*}\right)$ and polymicrobial growth is significantly more in diabetics $(\mathrm{p}=$ $0.029 *$ )

According to Miquel et al there was no significant difference in need of intensive care (ICU) requirement in between the two groups. ${ }^{11}$ Potgieter et al stated that Klebsiella and Staphylococcal pneumonia in diabetic patients has more severe course of disease and more often required mechanical ventilator support. ${ }^{15}$ Even in our study there were more number of ICU admissions among patients with diabetes but this was not significant statistically. 
Koziel $\mathrm{H}$ et al stated that the usual complications of pneumonia in diabetics were synpneumonic effusion, pyothorax and sepsis. ${ }^{16}$ Miquel et al also said that pleural effusion was considerably more in patients with diabetes. ${ }^{11}$ Present study also showed that there was slightly more complications in diabetic group but they were statistically insignificant.

According Miquel et al, majority of non-diabetics have less severe presentation in the form of lower PSI class (class I) whereas more severe presentations in diabetics with PSI class IV. ${ }^{11}$ The present study also shows that large number of nondiabetics fall under PSI class I in whereas majority of diabetic patients with pneumonia presented with class IV and class $\mathrm{V}$ which was statistically significant. Kornum JB et al did a casecontrol study which included 34,239 patients found that risk and prolonged hospitalization is associated with diabetes. ${ }^{17}$ In the present study also diabetic group had required more number hospital stay than non-diabetic patients.

Jensen AV et all had conducted multicenter prospective cohort study in Germany and Austria including 1961 patients with CAP found that diabetics had a higher six months mortality rate compared to non-diabetics $(12.1 \%$ vs. $3.8 \%$, respectively; $\mathrm{p}=0.001) .{ }^{18}$ Miquel et al also reported more deaths among diabetic patients. ${ }^{11}$ Akbar $\mathrm{DH}$ in contrast, reported that there was no significant difference in mortality between two groups. ${ }^{11}$ Even in our study more deaths were observed in diabetic patients but it was statistically not significant.

\section{CONCLUSIONS}

These is a significant difference between pneumonia in diabetics as compared to that in non-diabetics. Diabetic patients had presented with higher PSI score, required more ICU admissions and prolonged hospitalization. Diabetes is also associated with poor prognosis and high mortality.

Data sharing statement provided by the authors is available with the full text of this article at jemds.com.

Financial or other competing interests: None.

Disclosure forms provided by the authors are available with the full text of this article at jemds.com.

\section{REFERENCES}

[1] Musher DM, Thorner AR. Community-acquired pneumonia. N Engl J Med 2014;371(17):1619-28.

[2] Mason CM, Nelson S. Pulmonary host defenses and factors predisposing to lung infection. Clin Chest Med 2005;26(1):11-7.

[3] Almirall J, Bolíbar I, Balanzó X, et al. Risk factors for community acquired pneumonia in adults: a population- based case-control study. Eur Respir J 1999;13(2):34955.

[4] Carey IM, Critchley JA, DeWilde S, et al. Risk of infection in type 1 and type 2 diabetes compared with the general population: a matched cohort study. Diabetes Care 2018;41(3):513-21.

[5] Delamaire M, Maugendre D, Moreno M, et al. Impaired leucocyte functions in diabetic patients. Diabet Med 1997;14(1):29-34.

[6] Abu-Ashour W, Twells LK, Valcour JE, et al. Diabetes and the occurrence of infection in primary care: a matched cohort study. BMC Infect Dis 2018;18(1):67.

[7] Martin ET, Kaye KS, Knott C, et al. Diabetes and risk of surgical site infection: a systematic review and metaanalysis. Infect Control Hosp Epidemiol 2016;37(1):8899.

[8] The expert committee on the diagnosis and classification of diabetes mellitus. Report of the expert committee on the diagnosis and classification of diabetes mellitus. Diabetes Care 2007;30:S42-S46.

[9] American Diabetes Association. 2. Classification and diagnosis of diabetes: standards of medical care in diabetes-2020. Diabetes Care 2020;43(Suppl 1):S14-S31.

[10] Fine MJ, Auble TE, Yealy DM, et al. A prediction rule to identify low-risk patients with community-acquired pneumonia. N Engl J Med 1997;336(4):243-50.

[11] Falguera M, Pifarre R, Martin A, et al. Etiology and outcome of community-acquired pneumonia in patients with diabetes mellitus. Chest 2005;128(5):3233-9.

[12] Akbar DH. Bacterial pneumonia: comparison between diabetics and non-diabetics. Acta Diabetol 2001;38(2):77-82.

[13] Saibal MA, Rahman SHZ, Nishat L, et al. Community acquired pneumonia in diabetic and non-diabetic hospitalized patients: presentation, causative pathogens and outcome. Bangladesh Med Res Counc Bull 2012;38(3):98-103.

[14] Sohn JW, Park SC, Choi YH, et al. Atypical pathogens as etiologic agents in hospitalized patients with communityacquired pneumonia in Korea: a prospective multi-center study. J Korean Med Sci 2006;21(4):602-7.

[15] Potgieter PD, Hammond JM. Etiology and diagnosis of pneumonia requiring ICU admission. Chest 1992;101(1):199-203.

[16] Koziel H, Koziel MJ. Pulmonary complications of diabetes mellitus. pneumonia. Infect Dis Clin North Am 1995;9(1):65-96.

[17] Kornum JB, Thomsen RW, Riis A, et al. Diabetes, glycemic control and risk of hospitalization with pneumonia: a population- based case- control study. Diabetes Care 2008;31(8):1541-5.

[18] Jensen AV, Faurholt-Jepsen D, Egelund GB, et al. Undiagnosed diabetes mellitus in community- acquired pneumonia: a prospective cohort study. Clin Infect Dis 2017;65(12):2091-8. 